\title{
miR-132-3p mediates Functions of Vascular Smooth Muscle Cells through targeting PTEN expression and ERK1/2 pathway
}

\section{Guang liu}

Shanghai Jiao Tong University School of Medicine

zhijun He

shanghai zhoupu hospital

\section{Rong zhang}

shanghai fengcheng hospital

ganglion Yang

shanghai ninth people's hospital shanghai jiaotong university

sheng Huang

shanghai ninth people's hospital shanghai jiaotong university

huaxiang Lu

shanghai ninth people's hospital shanghai jiaotong university

xinwu lu

shanghai ninth people's hospital shanghai jiaotong university

yanli luo ( $\triangle$ luoyanli2000@163.com )

department of pathology, shanghai sixth people's hospital https://orcid.org/0000-0003-3606-4658

xiaobing liu

shanghai ninth people's hospital shanghai jiaotong university

\section{Research article}

Keywords: miR-132-3p, functions, PTEN, Vascular Smooth Muscle Cells, ERK1/2 pathway, vascular disease

Posted Date: June 9th, 2020

DOI: https://doi.org/10.21203/rs.3.rs-26165/v1

License: (c) (1) This work is licensed under a Creative Commons Attribution 4.0 International License.

Read Full License 


\section{Abstract \\ Background}

This study was aimed to investigate the functional role of the microRNA (miR)-132-3p in rat vascular smooth muscle cells (VSMCs) and the potential mechanisms in abdominal aortic aneurysm (AAA).

\section{Methods}

VSMCs were transfected with miR-132-3p mimics and inhibitors, and the effects of miR-132-3p on VSMCs proliferation, migration were assessed by CCK-8 assay and Boyden chamber cell invasion assay, respectively. miRNA targets were determined using bioinformatics and luciferase reporter assays. The protein expression of phenotype markers and related signaling pathways were detected by Western blot.

\section{Results}

Overexpression of miR-132-3p in VSMCs attenuated VSMCs proliferation and migration. Conversely, the opposite effect was obtained with the inhibition of miR-132-3p. We further demonstrated that miR-132 could significantly promote the expression of VSMCs marker genes ACTA2 and MYH1. Reporter assays and western blot validated that PTEN as a direct target of miR-132-3p in VSMCs. Besides, miR-132-3p overexpression could also promote the expression of ras and c-myc, and activate the phosphorylation levels of ERK $1 / 2$.

\section{Conclusions}

These results indicate that miR-132-3p is a critical regulator in maintaining normal functions of VSMCs through PTEN-ERK1/2 axis. Restoring expression of miR-132-3p may serve as a potential therapeutic approach for treatment of AAAs.

\section{Background}

Abdominal aortic aneurysm (AAA) rupture is one of the major causes of death in elderly people[1, 2]. Although current frontline therapy options such as surgery and endovascular treatment have been improved greatly in recent years, the molecular mechanism responsible for AAA formation is still unclear, which makes the development of medical therapies much slower 3 . Aneurysm formation is a complicated multifactorial progressive process involving destructive remodeling of the connective tissue around the affected segment of the aorta wall, characterized by dysfunctions in the vascular smooth muscle cells(VSMCs) which may be responsible for the progression of AAAs $[2,3,4]$. 
MicroRNAs (miRNAs) are single-stranded RNA molecules of approximately 19-25 nucleotides in length that can mediate multiple cellular processes, including proliferation, differentiation and apoptosis $[5,6]$. A number of normally expressed miRNAs have been reported in the cardiovascular system, to attune VSMCs phenotypes and functions and to be abnormally expressed in vascular diseases [7-11]. miRNAs could make a precise regulation of the intricate molecular networks by modulating mRNA and/or protein levels at the post-transcriptional level.

miR-132-3p was first identified with a 7-fold high expression in a rat AAA model in our previous study, but its role in AAAs formation is not fully understood [10]. Therefore, further study of the effect of miR-132-3p on VSMCs functions will help us understand its molecular mechanism in the formation of AAAs and develop new diagnostic and therapeutic approaches. In the present study, we demonstrated that miR-132$3 p$ could mediate VSMCs function, activate ERK1/2 signaling pathway and directly target phosphatase and tensin homolog (PTEN), which might be a new therapeutic target for AAAs.

\section{Results}

\section{miR-132-3p mediates VSMCs proliferation and migration.}

The miR-132-3p mimic, inhibitor and control were transfected into VSMCs, and the expression of miR132-3p was verified by qRT-PCR. Figure 1 (A) shows that the level of miR-132-3p expression was significantly downregulated in cells transfected with the miR-132-3p inhibitor. When the miR-132-3p mimic was transfected, the miR-132-3p level was remarkably increased compared to that in the control cells (Fig. 1B). A CCK-8 assay demonstrated that downregulation of miR-132-3p promoted cell proliferation, while the miR-221-3p mimic impaired cell proliferation on the contrary. (Fig. 1C) Moreover, inhabitation of miR-132-3p promoted VSMCs migration as assessed by Boyden chamber assays (Fig. 1D). In contrast, overexpression of miR-132-3p in VSMCs significantly attenuated VSMCs migration (Fig. 1E). Together, these data demonstrate that miR-132-3p is a potent inhibitor for VSMCs proliferation and migration.

\section{miR-132-3p regulates the expression of phenotype marker genes}

The modulation between a contractile phenotype and synthetic phenotype in smooth muscle cells was associated with changes in proliferation ability, migration capability, and expression level of VSMCs marker genes ${ }^{11}$. Smooth muscle a-actin (ACTA2) and smooth muscle myosin heavy chain (MYH11) were changed markedly during VSMCs phenotype modulation ${ }^{12,13}$. To reveal the role of miR-132-3p in regulating the expression of VSMCs marker genes, we transiently transfected rat VSMCs with miR-132-3p mimics or inhibitors for $72 \mathrm{~h}$. The expression levels of marker genes in VSMCs were examined by western blotting with ACTIN as the internal reference. The results showed that miR-132-3p downregulated the expression of contractile phenotype marker genes (Fig. 2A), while it upregulated that of synthetic 
phenotype marker genes (Fig. 2B). Our findings showed that overexpression of miR-132-3p by mimics significantly attenuated contractile marker expression in cultured VSMCs.

\section{PTEN was a target of miR-132-3p}

Among predicated candidate genes, we found that the gene encoding PTEN harbored a potential miR132-3p binding site. The alignment of miR-132-3p and the 3'-UTR of PTEN was shown of Fig. 3A. Next, the wild type or mutant $3^{\prime} U T R$ of PTEN gene was cloned and inserted into pMIR reporter vector. The results showed that overexpression of miR-132-3p led to a diminish of the luciferase activity carrying the wild-type PTEN 3'UTR but had noticeable effect on the luciferase reporter with mutated PTEN 3'-UTR (Fig. 3B). Transfection of miR-132 mimic also decreased the protein amount of PTEN (Fig. 3C, D). Conversely, down-regulation of miR-132-3p inhibitor signifcantly increased the expression levels of PTEN (Fig. 3C, D). Therefore, our results indicated that PTEN might be a target of miR-132-3p in VSMCs.

\section{Overexpression of miR-132-3p activates ERK $1 / 2$ signaling pathway}

In this study, we also explored whether ERK signaling pathway activation was affected by miR-132-3p. Ras, c-Myc, ERK1/2 and p-ERK1/2 expression levels were measured in VSMCs by western blot analysis after transfection with miR-132-3p mimics, inhibitors or miR-control. Our results demonstrated that overexpression of miR-132-3p obviously activated ERK1/2 phosphorylation and promoted c-myc, ras protein level, whereas Erk1/2 protein were not significantly changed, (Fig. 4).

\section{Discussion}

Alterations of VSMCs structural and functional connectivity have previously been described to play a crucial role in the initiation and progression of cardiovascular diseases, such as atherosclerosis obliteran, restenosis, and hypertension $[11,14]$. VSMCs phenotypes can be switched to each other reversibly, and once irreversible transformation occurs, vascular disease occurs [15]. It has been shown that phenotypes of VSMCs change from the contractile to the synthetic phenotype contribute to atherosclerosis, aortic aneurysms, and neointimal proliferation $[16,17]$. Therefore, therapeutic strategies that regulate abnormal VSMCs phenotypic alterations hold great promise for impeding the progression of vascular diseases.

Previous studies demonstrated that miRNAs participated in regulating VSMCs phenotype alterations[18]. In line with these studies, our in vitro experiments further indicated that upregulation of miR-132-3p in VSMCs strongly upgraded the expression levels of SMC-specific genes, while down-regulation of miR132-3p had the reverse effect on these markers. In order to investigate the molecular mechanism of microRNA-132-3p in VSMCs function regulation, we identified PTEN as a direct downstream target of miR-132-3p

PTEN is a member of type-I protein tyrosine phosphatase (PTP) family, originally found as a tumorsuppressed gene, regulating tumorigenic functions, such as apoptosis, cell cycle, cell adhesion, and cell 
VSMCs[21, 22]. In our study, we confirmed that overexpression of miR-132-3p significantly represses PTEN expression in rat VSMCs and validated the transcription factor PTEN as a direct target of miR-132$3 p$ in VSMCs. Additionally, ectopic expression of miR-132-3p inhibited cell proliferation and decelerated VSMCs migration. Therefore, we may conclude miR-132-3p mediate the function and phenotype change of VSMCs via PTEN.

Extracellular signal-regulated kinase (ERK) 1/2signaling pathway plays a crucial role in phenotypic modulation in VSMCs[23], regulating both contractile[24] and synthetic markers[25].It has also been found highly expressed in AAA tissues, which is an important modulator of MMPs during AAA formation[26, 27].Interestingly,ERK1/2 pathway was negatively regulated as an important downstream target of PTEN in many diseases[28, 29]. Similarly, our results revealed that miR-132-3p could impede PTEN expression and promote ERK phosphorylation along with its downstream target genes activation (c-myc, ras). Therefore, these findings suggest that the inhibitory effects of overexpressed miR-132-3p on AAA formation likely result from a combination of its ability to target both PTEN and ERK1/2 pathway.

It should be noted that there are some limitations to our study. There were more than a hundred predicted targets for miR-132-3p according to the website tools used. Whether these unexamined target genes could participate in miR-132-3p mediated VSMCs function is unknown. Even among the confirmed genes in this study, their interactions are still unclear. These limitations will hopefully be addressed in future studies.

\section{Conclusions}

In conclusion, miR-132-3p serves as an important regulator of VSMCs proliferation, migration and promotes a VSMCs synthetic phenotype modulation through targeting PTEN- ERK1/2 axis. Therefore, restoring miR-132-3p expression in the VSMCs may become an attractive therapeutic approach for treatment of AAA.

\section{Methods}

\section{Cell culture and transfection}

Rat Aortic Smooth Muscle Cell lines (A7R5) were obtained from the Shanghai Institutes for Biological Sciences (Shanghai, China). The cells were cultured in DMEM supplemented with $10 \%$ fetal bovine serum (FBS) in a humidified atmosphere of $5 \% \mathrm{CO}_{2}$ at $37.5^{\circ} \mathrm{C}$. Rat-miR-132 mimics, miR-132-3p inhibitor and control mimics (NC) were synthesized by Genepharma (Shanghai, China). The sequences were as follows: miR-132-3p mimics, 5- UAACAGUCUACAGCCAUGGUCG-3'; miR-132-3p inhibitor, 5'CGACCAUGGCUGUAGACUGUUA-3'. Transfection was performed by lentiviral vectors with a concentration of $50 \mathrm{nM}$ (Invitrogen, CA, USA) according to the manufacturer's instructions. Quantitative real-time PCR (qRT-PCR) was used to determine the transfection efficiency. 
Cell viability assay and migration Assessment.

Cell suspension $(100 \mu \mathrm{L} /$ well) transfected with miR-132-3p or control miRNA mimics was innoculated in a 96-well plate. Add 10 $\mathrm{L}$ of the CCK-8 solution to each well of the plate. Cell viability was measured with absorbance at $450 \mathrm{~nm}$ using a microplate reader. Boyden chamber cell invasion assays were performed according to the manufacturer's protocol (Chemicon, Billerica, MA, USA). Briefly, VSMCs $\left(5 \times 10^{4}\right)$ transfected with $40 \mathrm{nmol} / \mathrm{L}$ indicated miR-132-3p or control for 48 hours, and 2,500 cells were placed into Boyden chambers. The migrated cell numbers were determined from three random fields.

\section{Quantitative Real-time PCR}

Total RNA from VSMCs was isolated using TRIzol reagent (Invitrogen, Waltham, MA, USA) according to the manufacturer's protocol. PrimeScript ${ }^{\mathrm{TM}}$ RT Master Mix and a SYBR ${ }^{\circledR}$ Premix Ex TaqTM II kit (TaKaRa Bio, Otsu, Shiga, Japan) were used to make reverse transcription. Then, miR-132-3p was detected by hairpin-it miRNA qRT-PCR kits (Genepharma, Shanghai, China). The samples were run on an ABI7500 Real-time PCR detection system (Applied Biosystems, Foster City, CA, USA) with the following conditions: $95^{\circ} \mathrm{C}$ for $5 \mathrm{~min}$, followed by 40 repetitions of $95^{\circ} \mathrm{C}$ for $5 \mathrm{~s}$ and $60^{\circ} \mathrm{C}$ for $20 \mathrm{~s}$. U6 and GAPDH were used as the internal controls.

\section{Western blot}

Cell extracts was extracted with RIPA buffer and measured with a BCA protein quantification kit (Thermo Scientific, Rockford, IL, USA). A total of $40 \mu \mathrm{g}$ of protein was subjected to SDS-PAGE electrophoresis and transferred to a PVDF membrane (Millipore, Boston, MA, USA). All the primary antibodies were obtained from Cell Signaling Technology (Danvers, MA, USA). The membranes were blocked with $5 \%$ non-fat milk and incubated with primary antibody at $4{ }^{\circ} \mathrm{C}$ overnight. Then, the membranes were incubated with HRPconjugated anti-rabbit or anti-mouse antibody (Santa Cruz Biotechnology, Santa Cruz, CA, USA).

\section{miRNA target prediction}

Online tools were used to predict potential binding sites of miR-132-3p using TargetScan (http://www.targetscan.org/) and Mircode (http://www.mircode.org/). The putative binding sites of target genes should have perfect pairing at the 5' 2-8 position of the miRNAs.

\section{Luciferase reporter assay}

Cells were plated in 100-mm cell culture dishes and co-transfected with reporter construct using Lipofectamine 2000 (Invitrogen, Carlsbad, CA, USA) according to the manufacturer's protocol. The cells were harvested after a $24 \mathrm{~h}$ post-transfection. Dual Luciferase Assay (Promega,WI) was performed to testify Luciferase and Renilla luciferase activities according to the manufacturer's instructions.Relative firefly luciferase values were reported as final results, which were normalized to the Renilla luciferase activity. All transfection assays were repeated in three times.

\section{Statistical analysis}


Data were expressed as the means \pm standard deviations. A student's $t$ test or one-way ANOVA was used to compare variables. Differences were considered to be statistically significant at $P$-values $<0.05$. All statistical analyses were performed using the SPSS statistical package (version 18.0; SPSS Inc., Chicago, Illinois).

\section{Declarations}

\section{Ethics approval and consent to participate}

This experimental research on SD Rat cells was complied with the revised Animals (Scientific Procedures) Act 1986 in the UK and Directive 2010/63/EU in Europe) and was approved with Shanghai Ninth people's Hospital ethics committee.

\section{Consent for publication}

Not Applicable

\section{Availability of data and materials}

Materials described in the manuscript, including all relevant raw data, will be freely available to any scientist wishing to use them for non-commercial purposes, without breaching participant confidentiality.

\section{Competing interests}

The authors declare that they have no competing interests.

\section{Funding}

The study was funded by the Project of National Science Foundation of China (No. 81100223), the Science and Research Fund of Shanghai Municipal Commission of Health and Family Planning (201640078). The funder had no role in study design, data collection and analysis, decision to publish, or preparation of the manuscript.

\section{Contributions}

Data collection: SH; GL;XBL; RZ.

Data analysis: GL Y; HXL.

Study design: GL; YLL; ZJ H; XWL.

Writing: GL; XBL; ZJH.

All authors have read and approved the manuscript. 
Non

\section{Authors' Information}

Guang Liu*1,2 MD, PhD; Zhijun He ${ }^{\star 3}$, MD; Rong Zhang ${ }^{\star 2,4}$, MD;Guanglin Yang ${ }^{\star 1,2}$ MD, PhD; Sheng Huang 1,2,MD, PhD; Huaxiang Lu ${ }^{1,2}, \mathrm{MD}$; Xinwu Lu ${ }^{1,2}, \mathrm{MD}$, PhD; Yanli Luo ${ }^{5 * \star}$ MD, PhD; Xiaobing Liu ${ }^{\star * 1,2} \mathrm{MD}, \mathrm{PhD}$.

${ }^{1}$ Department of Vascular Surgery, Shanghai Ninth People's Hospital, Shanghai Jiao Tong University School of Medicine.

${ }^{2}$ Vascular Surgery Center in Fengxian District, Shanghai

${ }^{3}$ Department of General Surgery, Shanghai University of Medicine \& Health Sciences affiliated Zhoupu Hospital

${ }^{4}$ Department of Vascular Surgery, Fengcheng Hospital affiliated to Shanghai Ninth People's Hospital, Shanghai Jiao Tong University School of Medicine.

${ }^{5}$ Department of Pathology, Shanghai Jiao Tong University Affiliated Sixth People's Hospital

*These authors contributed equally to this work.

** Co-correspondence should be addressed to Yanli Luo PhD, MD, and Xiaobing Liu PhD,MD.

Contact Information for the Corresponding Author: Yanli Luo PhD,MD, and Xiaobing Liu PhD,MD.

Address: Department of Pathology, Shanghai Jiao Tong University Affiliated Sixth People's Hospital, No. 600 Yishan Rd,Shanghai 200233, P.R. China. \& Department of Vascular Surgery, Shanghai Ninth People's Hospital, Shanghai Jiao Tong University School of Medicine. No. 639 Zhizaoju Rd, Shanghai, P.R.China, 200011

E-mail|luoyanli2000@163.com(Yanli Luo MD) and benny_liuxb@163.com (Xiaobing Liu PhD,MD).

Phone: +86 2153315591 Fax: +86 02163087768

\section{References}

1. Verhoeven EL, Kapma MR, Groen H, Tielliu IF, Zeebregts CJ, Bekkema F, et al. Mortality of ruptured abdominal aortic aneurysm treated with open or endovascular repair. J Vasc Surg. 2008;48(6):1396400.

2. Golledge J. Abdominal aortic aneurysm: update on pathogenesis and medical treatments. Nat Rev Cardiol. 2019;16(4):225-42.

3. Golledge J, Norman PE. Atherosclerosis and abdominal aortic aneurysm: cause, response, or Loading [MathJax]/jax/output/CommonHTML/jax.js nb Vasc Biol. 2010;30(6):1075-7. 
4. Ward MR, Pasterkamp G, Yeung AC, Borst C. Arterial remodeling. Mechanisms and clinical implications. Circulation. 2000;102(10):1186-91.

5. LAI EC. MicroRNAs are complementary to 3' UTR sequence motifs that mediate negative post-transcriptional regulation. Nat Genet. 2002;30(4):363-4.

6. Lagos-Quintana M, Rauhut $R$, Lendeckel $W$, Tuschl $T$. Identification of novel genes coding for small expressed RNAs. Science. 2001;294(5543):853-8.

7. Joviliano EE, Ribeiro MS, Tenorio EJR. MicroRNAs and Current Concepts on the Pathogenesis of Abdominal Aortic Aneurysm. Braz J Cardiovasc Surg. 2017;32(3):215-24.

8. Adam M, Raaz U, Spin JM, Tsao PS. MicroRNAs in Abdominal Aortic Aneurysm. Curr Vasc Pharmacol. 2015;13(3):280-90.

9. Kang $\mathrm{H}$, Hata A. MicroRNA regulation of smooth muscle gene expression and phenotype.Curr. Opin Hematol. 2012;19(3):224-31.

10. Liu G, Huang Y, Lu X, Lu M, Huang X, Li W, Jiang M. Identification and characteristics of microRNAs with altered expression patterns in a rat model of abdominal aortic aneurysms. Tohoku J Exp Med. 2010;222(3):187-93.

11. Owens GK, Kumar MS, Wamhoff BR. Molecular regulation of vascular smooth muscle cell differentiation in development and disease. Physiol Rev. 2004;84(3):767-801.

12. Wamhoff BR, Hoofnagle MH, Burns A, Sinha S, McDonald OG, Owens GK. A G/C element mediates repression of the SM22alpha promoter within phenotypically modulated smooth muscle cells in experimental atherosclerosis. Circ Res. 2004;95(10):981-8.

13. Gomez D, Owens GK. Smooth muscle cell phenotypic switching in atherosclerosis. Cardiovasc Res. 2012;95(2):156-64.

14. Orr AW, Hastings NE, Blackman BR, Wamhoff BR. Complex regulation and function of the inflammatory smooth muscle cell phenotype in atherosclerosis. J Vasc Res. 2010;47(2):168-80.

15. Lv P, Zhang F, Yin YJ, Wang YC, Gao M, Xie XL, et al. SM22a inhibits lamellipodium formation and migration via Ras-Arp2/3 signaling in synthetic VSMCs. Am J Physiol Cell Physiol. 2016;311(5):C758-67.

16. Regan CP, Adam PJ, Madsen CS, Owens GK. Molecular mechanisms of decreased smooth muscle differentiation marker expression after vascular injury. J Clin Invest. 2000;106(9):1139-47.

17. Gorav Ailawadi CW, Moehle H, Pei SP, Walton Z, Yang, et al. Smooth muscle phenotypic modulation is an early event in aortic aneurysms. J Thorac Cardiovasc Surg. 2009;138(6):1392-9.

18. Joshi SR, Comer BS, McLendon JM, Gerthoffer WT. MicroRNA Regulation of Smooth Muscle Phenotype. Mol Cell Pharmacol. 2012;4(1):1-16.

19. Deevi R, Fatehullah A, Jagan I, Nagaraju M, Bingham V, Campbell FC. PTEN regulates colorectal epithelial apoptosis through Cdc42 signalling. Br J Cancer. 2011;105(9):1313-21.

20. Bowen KA, Doan HQ, Zhou BP, Wang Q, Zhou Y, Rychahou PG, Evers BM. PTEN loss induces enithelial-mecenchumal trancition in human colon cancer cells. Anticancer Res. 2009;29(11):4439Loading [MathJax]/jax/output/CommonHTML/jax.js 
49.

21. Huang J, Kontos CD. Inhibition of vascular smooth muscle cell proliferation, migration, and survival by the tumour suppressor protein pten. Arterioscler Thromb Vasc Biol Arterioscler Thromb Vasc Biol. 2002;22(5):745-51.

22. Horita H, Wysoczynski CL, Walker LA, Moulton KS, Li M, Ostriker A, Tucker R, McKinsey TA, Churchill ME, Nemenoff RA, Weiser-Evans MC. Nuclear PTEN functions as an essential regulator of SRFdependent transcription to control smooth muscle differentiation. Nat Commun. 2016;7:10830.

23. Roy J, Kazi M, Hedin U, Thyberg J. Phenotypic modulation of arterial smooth muscle cells is associated with prolonged activation of ERK1/2. Differentiation. 2001;67(1-2):50-8.

24. Schauwienold D, Plum C, Helbing T, Voigt P, Bobbert T, Hoffmann D, Paul M, Reusch HP. ERK1/2dependent contractile protein expression in vascular smooth muscle cells. Hypertension. 2003;41(3):546-52.

25. Moses S, Franzén A, Lövdahl C, Hultgårdh-Nilsson. A.Injury-induced osteopontin gene expression in rat arterial smooth muscle cells is dependent on mitogen-activated protein kinases ERK1/ERK2. Arch Biochem Biophys. 2001;396(1):133-7.

26. Ghosh A, DiMusto PD, Ehrlichman LK, Sadiq O, McEvoy B, Futchko JS, Henke PK, Eliason JL, Upchurch GR Jr. The role of extracellular signal-related kinase during abdominal aortic aneurysm formation. J Am Coll Surg. 2012;215(5):668-80.e1.

27. Ehrlichman LK, Ford JW, Roelofs KJ, Tedeschi-Filho W, Futchko JS, Ramacciotti E, Eliason JL, Henke PK, Upchurch GR Jr. Gender-dependent differential phosphorylation in the ERK signaling pathway is associated with increased MMP2 activity in rat aortic smooth muscle cells. J Surg Res. 2010;160(1):18-24.

28. Chetram MA, Hinton CV. PTEN regulation of ERK1/2 signaling in cancer. J Recept Signal Transduct Res. 2012;32(4):190-5.

29. Li ZH, Li L, Kang LP,Wang Y. MicroRNA-92a promotes tumor growth and suppresses immune function through activation of MAPK/ERK signaling pathway by inhibiting PTEN in mice bearing U14 cervical cancer. Cancer Med. 2018;7(7):3118-31.

\section{Figures}



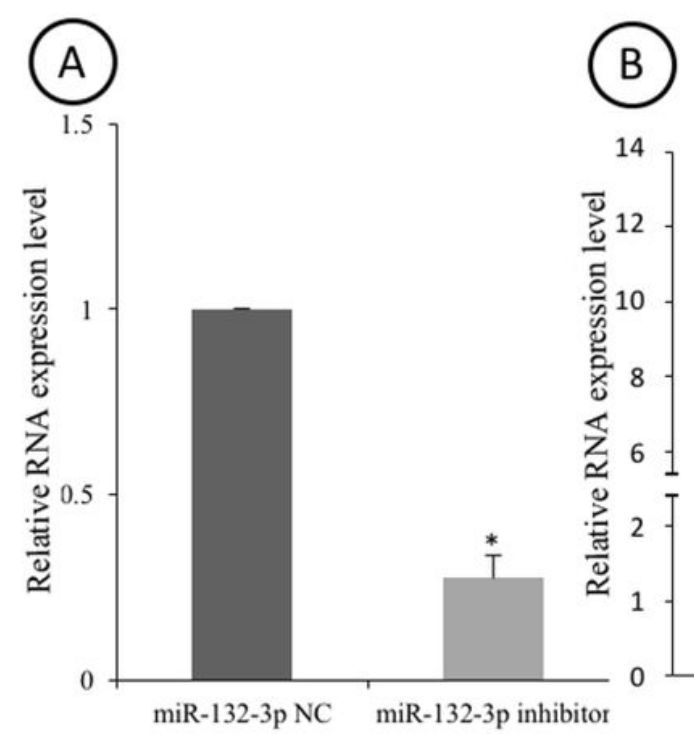

(C)
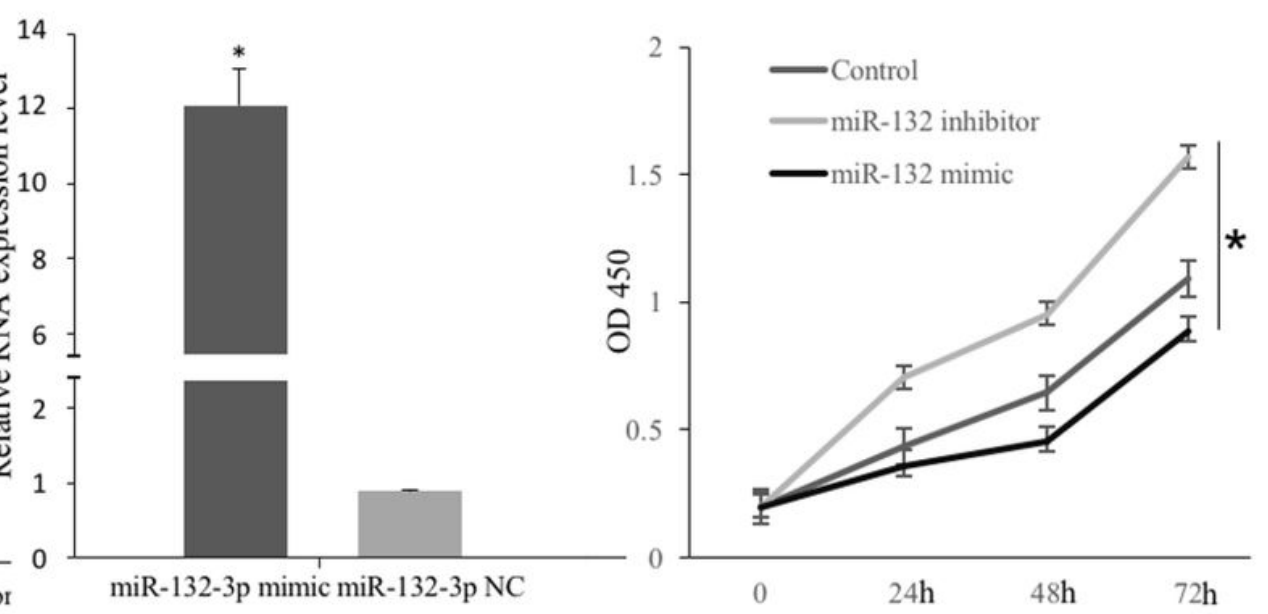

(D)

Migrated Cells/ Field

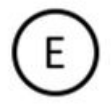

Migrated Cells/ Field
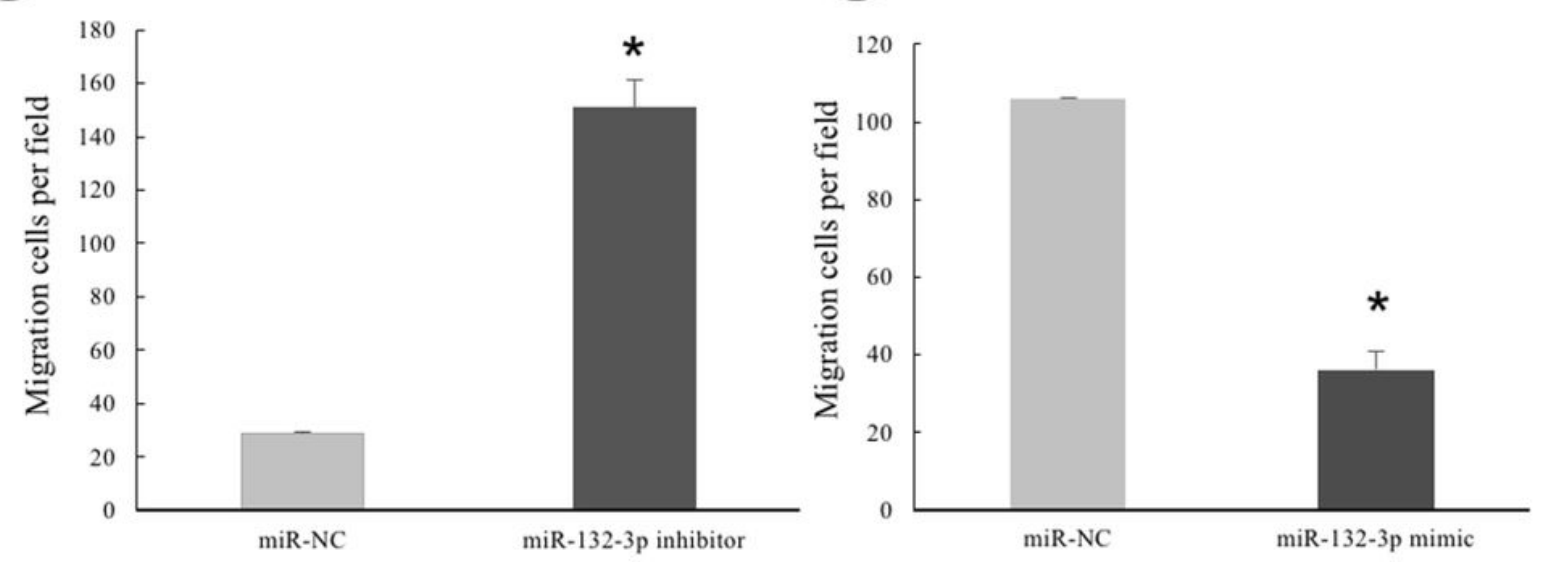

Figure 1

miR-132-3p regulates VSMCs proliferation and migration. (A-B. The expressions of miR-132-3p in VSMCs lines transfected with miR-132-3p mimic or inhibitor detected by RT-qPCR. (C). VSMCs proliferation was increased by a miR-132-3p inhibitor and decreased by miR-132-3p mimics. Cell proliferation was detected with a CCK-8 assay. (D-E). The Boyden chamber assay was performed to assess cell migration.

Overexpression of miR-132-3p in VSMCs significantly attenuated VSMCs migration. ${ }^{*} \mathrm{P}<0.05$. 
A

ACTA2

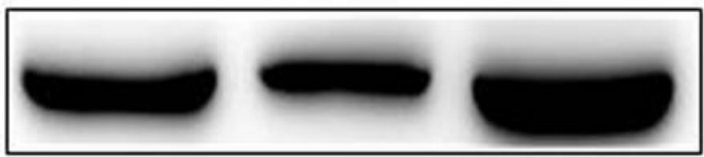

MYH11

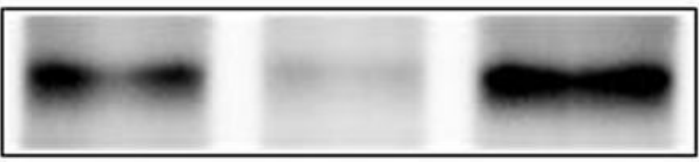

ACTIN

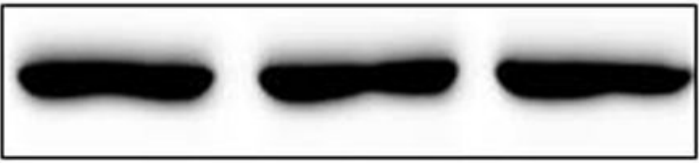

NC miRNA-132-3p miRNA-132-3p

inhibitor

mimic

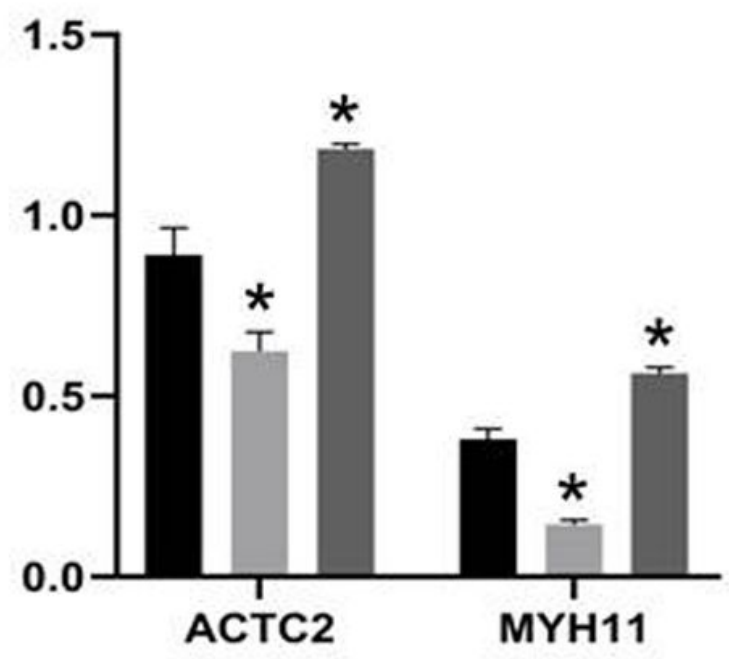

- NC

miRNA-132-3p inhibitor

- miRNA-132-3p mimic

B

Figure 2

miR-132-3p modulates the expression of phenotype marker genes. (A) Overexpression and inhibition of miR-132-3p, respectively, promotes and inhibits ACTA2 and MYH11 expression in VSMCs. (B) Densitometric analysis of VSMCs marker genes ACTA2 and MYH11. ${ }^{*} \mathrm{P}<0.05$. (Original pictures can be found in Supplementary s-fig2 ). 


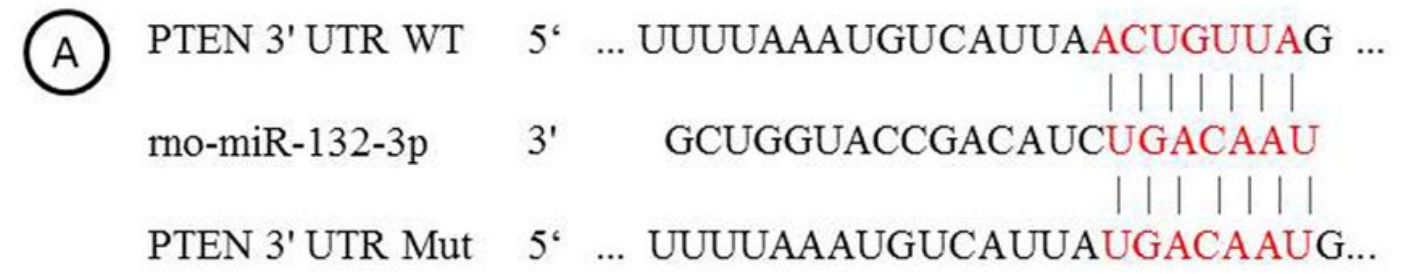
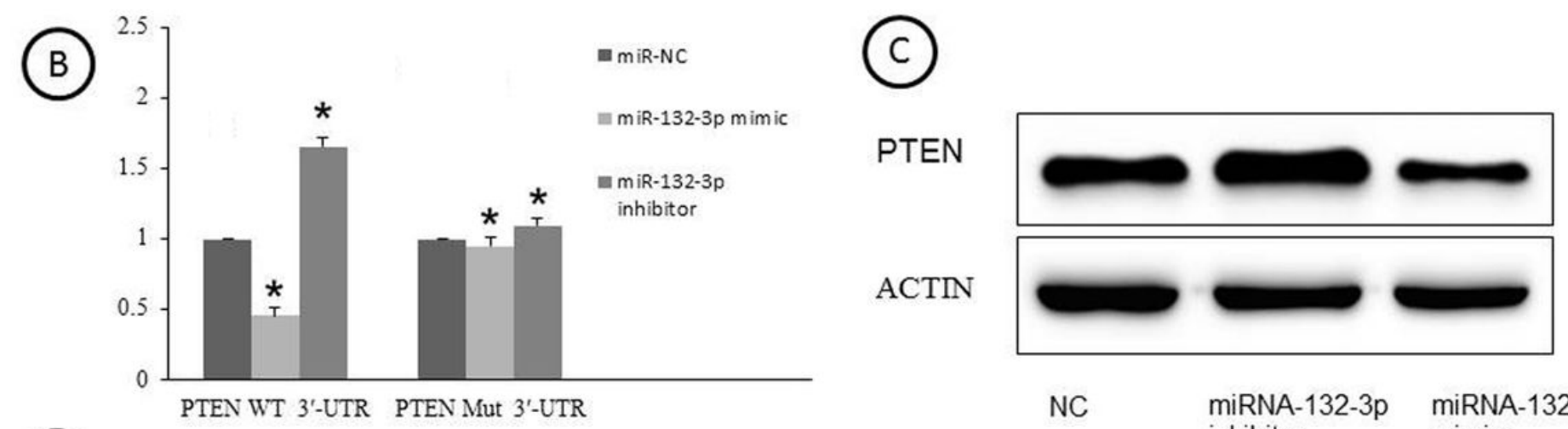

NC

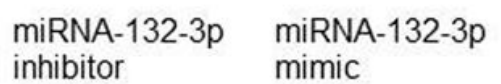

(D)

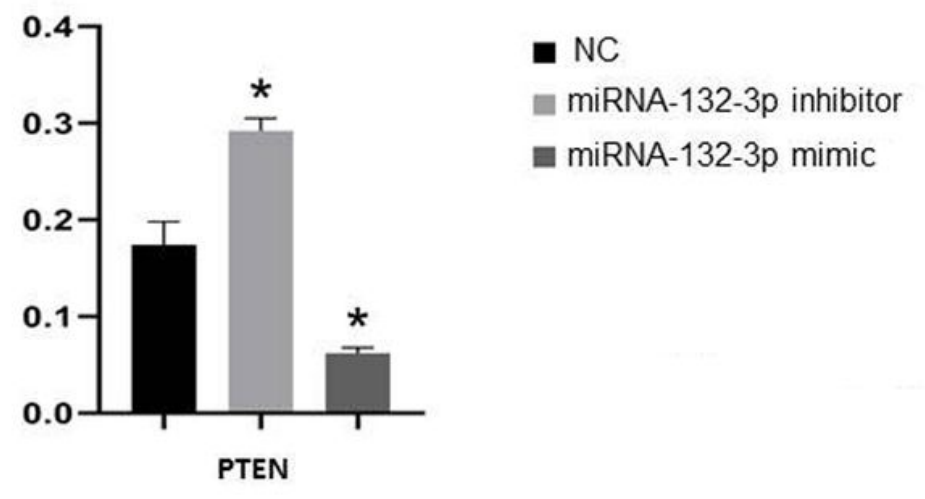

\section{Figure 3}

PTEN acts as a direct target gene of miR-132-3p.(A) Position of predicted miR-132-3p target sites in the 3'-UTRs of PTEN. (B) Luciferase activities were detected using qRT-PCR. (C) The protein levels of PTEN was examined by Western blot in cells transfected with NC or miR-132 mimic or inhibitor. (D) Densitometric analysis of PTEN expression. ${ }^{*} \mathrm{P}<0.05$. (Original pictures can be found in Supplementary sfig3). 


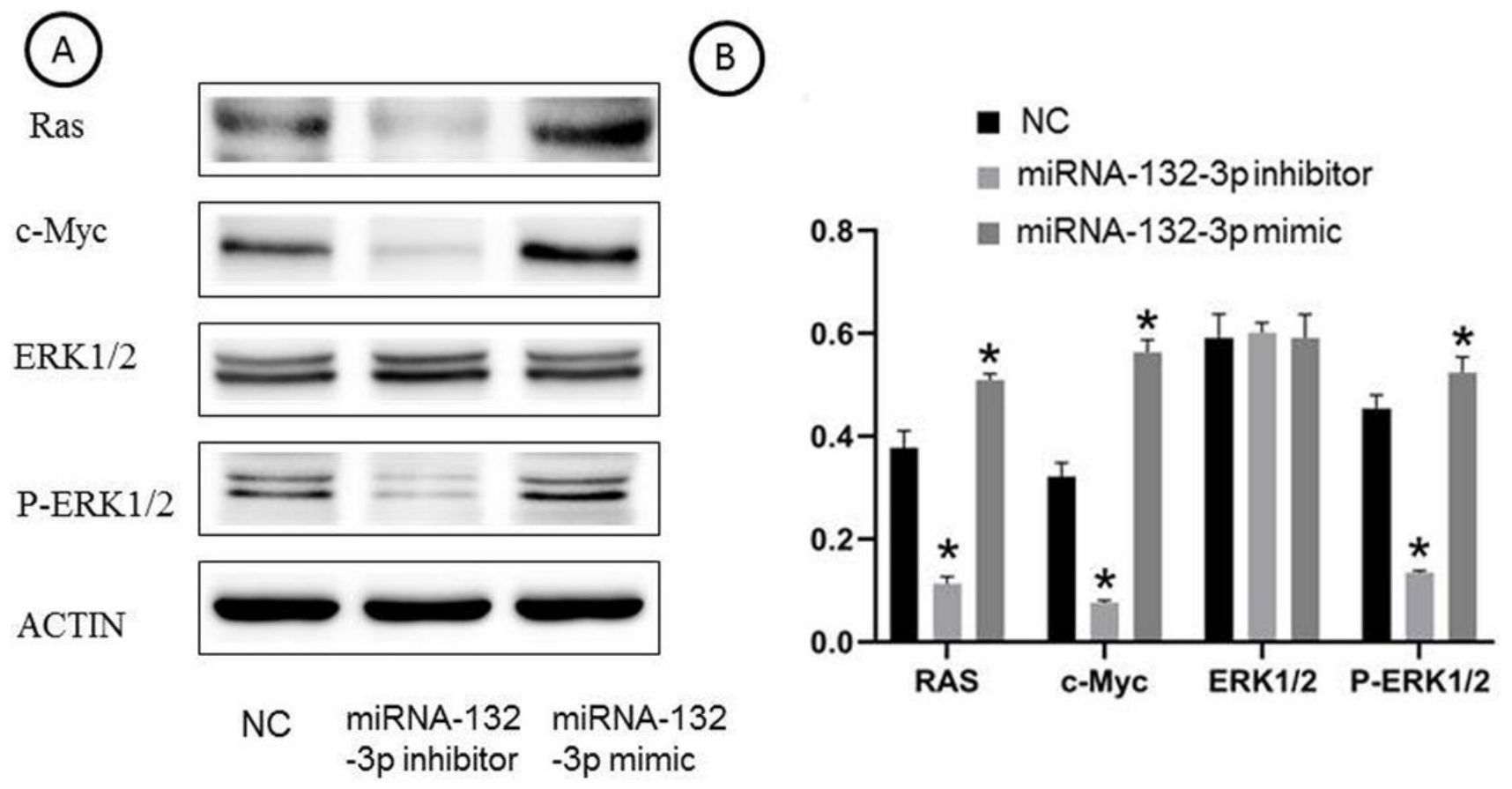

Figure 4

ERK1/2 signaling pathway is regulated by miR-132-3p. (A)Total levels of Erk1/2 protein were not significantly changed, whereas $\mathrm{p}$-ERK1/2 was up-regulated in miR-132-3p mimic cells. Expression of cmyc and ras was increased in miR-132-3p overexpression cells, compared to miR-132 NC and inhibitor cells. (B) Densitometric analysis of ERK1/2, c-myc and ras expression. ${ }^{*} \mathrm{P}<0.05$. (Original pictures can be found in Supplementary s-fig4 ).

\section{Supplementary Files}

This is a list of supplementary files associated with this preprint. Click to download.

- supplement1.jpg

- supplement2.pdf

- supplement3.pdf

- supplement4.tif

- supplement5.tif

- supplement6.tif

- supplement7.tif

- supplement8.tif

- supplement9.tif 
- supplement11.tif

- supplement12.tif

- supplement13.tif

Loading [MathJax]/jax/output/CommonHTML/jax.js 